\title{
POLÍTICA EDUCACIONAL DA IDENTIDADE E DO MULTICULTURALISMO
}

\author{
JOHN WILLINSKY \\ University of British Columbia - Vancouver, Canadá \\ john.willinsky@ubc.ca
}

Tradução: Maria Lúcia Mendes Gomes e Vera L. Visockis Macedo*

\section{RESUMO}

Oartigo procura desvendar o novo impacto educacional que pode causar politicas de identidade e multiculturalismo, argumentando que é preciso prover a nova abordagem com a compreensão da forma como categorias de peso como cultura, raça e nação vêm sendo construídas. Para tanto, recorre à posição filosófica de Simone Weil, a qual defende a necessidade de partir das "raízes" para aprender a conhecer as qualidades éticas da categoria da identidade. Contrapõese, nesse sentido, à política de identidade de Taylor, que busca reconciliar o individualismo liberal com os direitos coletivos e que informa as iniciativas multiculturais e anti-racistas de duas secretarias de educação de províncias canadenses. Revê ainda as críticas ao multiculturalismo de Bissoondath e Schlesinger, expondo a posição dos autores sobre nacionalismo ético. Finalmente admite: por mais obscura que possa ser a prioridade educacional dada à descoberta dos processos politicos, incluindo-se a própria escolarização, ela confere força e significância pessoal a importantes aspectos da identidade.

MULTICULTURALISMO-IDENTIDADE-CULTURA-RAÇA

\section{ABSTRACT}

EDUCATIONAL POLITICSOFIDENTITY AND CATEGORY. Thispaper attempts to uncoveranew educational impact through the politics of identity and multiculturalism by arguing that is necessary to equip the young with an understanding of how powerful categories - such as culture, race and nation - have been constructed. It is based on the philosophical position of Simone Weil, which defends the need of roots in order to establish the importance of learning to judge ethical qualities of the category of identify. It then turns this position against the shortcomings of Charles Taylor's politics of recognition, in its attempt to reconcile liberal individualism with collective rights. Proceeding into the arena of public policy, the paper applies these philosophical perspectives to the multicultural and anti-racist initiatives of two Canadian provincial Ministries of Education. Finally, it reviews the

Artigo publicado em inglês na Interchange, v. 29/4, p.385-402, 1998, sob o título "The Educational politics of identity and category".

* As tradutoras deste artigo são membros da Cooperativa de Profissionais em Tradução - Unitrad. (unitrad@unitrad.com.br) 
impassioned critiques of multiculturalism by Neil Bissoondath and Arthur Schlesinger, exposing the currents of ethic nationalism, wich underwrite their position. As obscure as it can be the educational priority given to the discovery of the political process, including schooling itself, it gives public weight and personal significance to important points of identity.

MULTICULTURALISM-IDENTITY - CULTURE-RACE

Dificilmente, Simone Weil pode ser incluída no rol de filósofos-heróis da França do século $X X$. Ela não ocupou as primeiras páginas dos jornais como Simone de Beauvoir e Jean-Paul Sartre, marchando nas ruas de Paris durante as demonstrações de 1968. Nem foi presa com grande publicidade, como aconteceu a Michel Foucault em frente à Prisão La Santé, como se soube mais tarde, por não ter registrado os direitos autorais de seus panfletos, protestando contra o tratamento desumano dispensado aos prisioneiros. O heroísmo de Weil limitou-se a ter abandonado uma carreira acadêmica promissora para trabalhar no setor de produção de uma fábrica da Renault, mesmo que só por um ano de sua breve vida. Ela abandonou a elite intelectual que freqüentava os cafés por acreditar que o cerne espiritual da vida seria encontrado no trabalho. Essa mesma qualidade subestimada, porém intensa, permeia seus altamente elogiados trabalhos escritos, todos publicados depois de sua morte, aos 33 anos de idade.

Era o ano de 1943 e ela se encontrava entre os refugiados judeus que trabaIhavam no quartel-general da França, em Londres. Sua saúde, já bastante debilitada, piorava gradualmente, pois ela insistia em restringir sua alimentação às rações permitidas a seus compatriotas na França ocupada. Trabalhava à época em um manuscrito, publicado postumamente (1952), intitulado The Need for roots [O Enraizamento]*. Esse último trabalho baseia-se na experiência de professores, de pessoas oriundas das colônias, de policiais, prostitutas, sindicalistas e surrealistas que the revelavam os valores e as mazelas da identidade coletiva. $\bigcirc$ livro constitui-se em um guia ético de como nos enraizamos no mundo e, como tal, esclarece consideravelmente a atual política de identidade e multiculturalismo em matéria de deslocamento e enraizamento.

O termo política da identidade é seguramente um termo novo, que entrou em voga no pós-modernismo, bem depois da época de Weil. Mas o conceito nada tem de novo, pois um século antes, na França, a política da identidade ocupou um papel central no Caso Dreyfus na Escola Militar, da mesma forma que está presente

* Os títulos de obra foram traduzidos no corpo do texto. Permanecem, contudo, no original, nas Referências Bibliográficas (N. da E.). 
na recente desfiguração das sinagogas francesas com suásticas. Essa é uma questão que se refere a saber quem pode, com tranqüilidade, afirmar ser totalmente francês. Tal como ocorreu com a emancipação dos judeus e a reação contrária dos antisemitas na França, no século XIX, a política da identidade tende a desenterrar as tradições já enraizadas que definem as pessoas segundo gênero, raça, cultura e nação. A política da identidade levanta a questão de como deveríamos ser conhecidos, assim considerados e tratados. Se os judeus, hoje em dia, não são mais considerados uma raça à parte, na maioria das vezes a luta pela identidade política a respeito de como as pessoas deveriam ser conhecidas continua, entretanto, em outras frentes. Tanto é assim que os elaboradores do censo norte-americano estão atualmente se esforçando para determinar como as pessoas identificarão sua "raça", em vista da instabilidade do termo e da complexidade de nossas genealogias, embora em alguns estados só seja preciso "uma gota" de sangue para uma pessoa ser legalmente considerada um afro-norte-americano perante as cortes de justiça (Wright, 1994). Houve tempo em que nada era mais óbvio do que as linhas divisórias entre os gêneros, raças e culturas; hoje, temos uma política de identidade que contesta as linhas divisórias e a importância da diferença. Esse tipo de política exige, no meu modo de ver, uma educação que corresponda ao por quê e o para quê de tais divisões. Ela sugere que perguntemos, da mesma forma que Edward Said perguntou em seu livro de referência, Orientalismo, se é possível

... dividir a realidade humana, como parecem na verdade, estar genuinamente dividida, de forma inequívoca, em diferentes culturas, histórias, tradições, sociedades, até mesmo raças, e humanamente sobreviver às conseqüências?. (1 978, p.45)

Uma forma de se abordar essa questão é a partir do status ou, como diz Said, do caráter genuíno das divisões. Embora elas certamente pareçam ter a força gravitacional da realidade - pense naqueles arrasados pela discriminação categórica - há muito em jogo para se aceitar essas divisões como um fato da natureza. Precisamos de um tipo de educação, e é o que proponho, que contemple a dinâmica histórica das categorias segundo as quais estamos divididos.

Daí meu interesse em Weil. As comunidades a que pertencemos e segundo as quais vivemos constituíram, afinal, o assunto de seu último trabalho. "Devemos respeito", afirma Weil logo no início de O Enraizamento, "a uma coletividade, seja de que tipo for - país, família ou qualquer outro tipo - não por ela mesma, mas porque é alimento para um certo número de almas humanas" ( I 952, p.7). Embora falar sobre a alma possa estar além do escopo normal do meu trabalho educacional, ao ler Weil, percebi que seu paralelismo entre alimento e alma demonstra uma 
sensibilidade ética que se pode facilmente perder quando as discussões de identidade giram em torno de política e poder, sangue e solo. Uma vez que alimenta a alma, uma "coletividade" precisa ser julgada com extremo cuidado por aquilo em que nos transforma, e Weil reserva-se o direito de questionar suas qualidades específicas. Algumas coletividades "devoram as almas", escrevia ela, enquanto a Alemanha nazista continuava sua marcha pela Europa, ao passo que outras estão simplesmente mortas para este mundo (p.9). E continuando, identifica as qualidades de coletividades vitais, de afirmação da vida, e entre essas qualidades eu destacaria a honra, embora possa parecer estranho à primeira vista, devido à forma como esta se relaciona diretamente com a atual política da identidade (p. 19).

É sem dúvida verdade que, no Caso Dreyfus, a honra da França parecia estar em jogo, e que um terrível senso de honra estava na raiz da visão dos nazistas arianos. Mas em ambos os casos, pode-se perceber claramente como a coletividade simplesmente não soube honrar todos aqueles aos quais tinha a responsabilidade de respeitar e proteger. A coletividade deve não apenas estar disposta a honrar todos que abriga, mas a mim parece que ela, considerando-se as lições da história, deve estar disposta a honrar seu passado, redimindo as inevitáveis desigualdades cometidas contra aqueles que não honrou. Weil aborda esse tema focalizando o tratamento concedido pela França "ao subproletariado, composto de imigrantes das colônias e nativos" como um momento particularmente desonroso para o país (p.20). A França abandonava aqueles a quem havia privado dos direitos que o império proporcionava, embora continuasse a exigir deles lealdade e serviço. Weil demonstra seu argumento voltando-se para as escolas francesas. Todas aquelas lições sobre Joana D'Arc, salienta ela, têm sua razão de ser quando são ensinadas àqueles que pertencem a esta nação, que são honrados por esta coletividade:

Atualmente, falamos sobre a heroína para os anamitas e os árabes; embora eles saibam muito bem que aqui na França não permitimos que falem sobre seus santos e heróis; assim sendo, a condição na qual os colocamos é uma afronta à sua honra. (p.20)

Isso soa familiar para aqueles que defenderam um currículo multicultural, pois esse tipo de afronta é há muito tempo peculiar aos sistemas nacionais de educação que, normalmente e sem nenhum pudor, fazem da cultura dominante do país o conteúdo integral do currículo. Weil interpela a França por não ter honrado aqueles por quem assumira responsabilidade, e sua crítica evidencia a necessidade de a nação reconhecer que honrar os mitos do passado não é tão importante quanto aceitar a responsabilidade pelo presente. 
Na conclusão de sua breve análise sobre a honra, Weil expressa preocupação quanto à "falta de respeito reservada a certas categorias de seres humanos" que se pode perpetuar em uma coletividade tal como uma nação (p.20). Sua resposta a essa falta de respeito é propor, de forma um tanto idealista, que "categorias desse tipo não deveriam existir" (p.20). Esse é um bom exemplo de como visionários moralistas podem às vezes parecer simplesmente ingênuos, e de quão útil essa ingenuidade pode mostrar-se para todos nós. Tomemos a denominação "imigrante", que para ela é uma das categorias que não deveria existir. Hoje, mais de meio século após Weil ter escrito sobre a honra devida a um povo, a imigração das antigas colônias dos impérios europeus permanece uma das maiores questões de discordância na Europa. Acho que não estou errado em dizer que muitas das nações não honram a si mesmas com sua mentalidade e políticas de uma Europa forte.

Ainda assim, dizer que "categorias desse tipo não deveriam existir" não ajuda muito quando se busca diminuir a influência dessas categorias em nossa linguagem e nossas mentes. A meu ver, trata-se de uma questão educacional relevante e espinhosa para a atual política de identidade. $\bigcirc$ que temos a responsabilidade de ensinar sobre essas categorias de modo que possam alimentar as almas das crianças de uma maneira que nós apoiaríamos? Com programas de educação multiculturais, por exemplo, estamos lutando para mudar o significado das categorias, vestir a pluralidade de culturas, raças e nacionalidades com cores gloriosas e orgulho, encontrar um lugar para essa pluralidade no currículo e no Estado. Mas e se essas categorias não devessem existir? Há lugar em nossas filosofias sobre multiculturalismo para questionar a existência dessas categorias pelas quais somos conhecidos?

Como você pode inferir, encontro parte da resposta na vida e nas idéias de Simone Weil. Partindo de seu exemplo, gostaria de afirmar que faríamos bem em nos concentrar na formação das categorias, e em nos empenharmos na construção educacional das categorias, como a contribuição mais eficaz que os educadores poderiam fazer à atual política da identidade. Pois embora Weil, com toda certeza, tenha falado sobre a necessidade de raízes, ela não dedicou sua vida à busca dessas raízes. Permaneceu comprometida com a investigação da natureza dessas formas de vida enraizadas. Do mesmo modo, embora preocupada com o desenraizamento imposto às pessoas, com relação a ela mesma, não tinha interesse em se acomodar, seja intelectual, seja espiritual, seja fisicamente. Estava dividida entre o judaísmo de sua família e sua própria vocação católica, entre seus brilhantes resultados acadêmicos nas melhores escolas da França e o trabalho no setor de produção da Renault. 
Ela buscou sem descanso o que significava reconhecer um lugar como sendo próprio da pessoa, um lugar não determinado pela geografia ou genealogia, mas pela contingência, pela ética e por uma escolha criteriosa. $O$ desejo de Weil não era o de encontrar seu lugar no mapa nem em qualquer coletividade. Era o de ajudar a pensar, por meio da necessidade e das conseqüências de tais mapas e coletividades, na vida das pessoas. Era o de julgar até que ponto essas associações estão a serviço das necessidades humanas. Essa abordagem pode parecer intelectual ou racional demais considerando-se a necessidade profunda de raízes, e no entanto isso é exatamente o que confere solidez a essa abordagem educacional para as políticas de identidade e multiculturalismo.

Para ilustrar rapidamente como Weil pode nos guiar nessas políticas, podemos analisar o fato de ter sido negado às adolescentes mulçumanas, em Paris, o direito de usarem o véu que lhes cobre a cabeça (hijab) na escola'. As estudantes estavam rompendo com a cultura secular da escola, como alegaram as autoridades educacionais, ou a nação não honrou a história e a religião dessas estudantes que ficaram inextrincavelmente ligadas à nação francesa e às influências de seu antigo império colonial? Por este ato, lembra-se às estudantes que não há lugar para elas na França, não há lugar para elas na cultura que a França define como sua. No entanto, aqui está a real oportunidade para a França, no espírito de Weil, redimir-se com honra por ter ela mesma abalado e desarraigado enormemente as culturas tradicionais em nome do imperialismo. A nação precisa honrar essas estudantes e a interseção das histórias que ampliou as nações tradicionais por meio de outras culturas nacionais. Uma França com três milhões de mulçumanos precisa repensar como honrará a necessidade de raízes de seus cidadãos. A nação é histórica, poderíamos dizer, somente quando muda com o passar do tempo. Para permanecer como vital, precisará instruir gerações sucessivas de estudantes na política da identidade, preparando-as para ler e questionar as mudanças da definição de nação, tanto quanto as outras categorias pelas quais são conhecidas. Este é o exemplo que se pode extrair de Weil, e esta é a abordagem educacional que deve, como continuarei a argumentar na seqüência, complementar o que os defensores e burocratas contemporâneos do multiculturalismo fazem com a política da identidade, para evitar que consigam apenas o fortalecimento das categorias dadas e questionáveis. Começarei com os defensores.

I Sobre a proibição do uso do véu pelas estudantes nas escolas da França e Quebec, consulte Narsulla, 1994. 


\section{O FILÓSOFO DO RECONHECIMENTO}

Recentemente, a honra às raízes recebeu tratamento filosófico de Charles Taylor, que tem sua própria história a contar sobre deslocamento e enraizamento. Taylor cresceu em Montreal, filho de mãe franco-canadense e pai anglo-canadense e atualmente leciona na McGill University, por si só um baluarte inglês na segunda maior cidade de língua francesa no mundo. Entre a política separatista e a soberania de Quebec, Taylor identifica o reconhecimento como um tema político básico em escala global, que guarda uma óbvia relação com a concepção de honra de Weil. "A política do reconhecimento", como Taylor coloca, trabalha "em prol de grupos minoritários ou 'subalternos', em algumas formas de feminismo e naquilo que hoje se denomina a política do multiculturalismo" (1994, p.25). Apoiando-se no lugarcomum da psicologia de que "nossa identidade é parcialmente formada pelo reconhecimento" e uma saudável dose de teoria política liberal, Taylor delineia a postura ética do multiculturalismo: "O não-reconhecimento ou o reconhecimento inadequado pode prejudicar, pode ser uma forma de opressão, aprisionando uma pessoa em um modo de ser falso, distorcido e limitado" (p.25).

A missão do multiculturalismo, então, poderia ser caracterizada como a de libertar os prisioneiros do reconhecimento inadequado. $\bigcirc$ reconhecimento da pluralidade cultural permitirá que aquelas pessoas aprisionadas em um modo de ser distorcido e limitado sejam aquilo que são, total e completamente. $O$ significado de ser o que se é na sua totalidade não é exatamente uma questão fácil e pretendo retomá-la depois de apresentar, de forma mais ampla, os argumentos de Taylor sobre modos de ser nas esferas políticas mais abrangentes da democracia. Ele afirma que "a democracia introduziu uma política de reconhecimento igual", e seu projeto principal é abranger, em cada aspecto, o "status igual de culturas e gêneros" (p.27). Porém, essa posição sensata e comum cria sua própria política de identidade que, a meu ver, enfraquece a posição de Taylor ao mesmo tempo que aponta, à maneira de Weil, para aquilo que precisa ser ensinado sobre cultura e outras coletividades dentro de uma democracia. A lição aqui diz respeito à tensão fundamental entre os direitos individuais e coletivos na democracia.

Embora Taylor apresente seu argumento sobre multiculturalismo com base no individualismo, que ele vê como presente no cerne das noções ocidentais modernas de moralidade e autenticidade, acho que a política da identidade traz um novo realismo para o sentido do que é individual versus coletivo (p.28). Considerese o modo pelo qual a democracia, apesar de toda sua celebração da individualidade, evoluiu para o sufrágio universal por meio de uma série de extensões rigorosa- 
mente categóricas do direito de voto para os destituídos, as mulheres e os nativos das colônias. Os argumentos em favor de estender esses direitos aos que antes não os tinham assumiam que essas pessoas estavam agora prontas, como grupo, a participar da autodeterminação. Os direitos universais do homem, celebrados pelos democratas europeus, nunca foram realmente universais, nem realmente relativos a indivíduos; tratava-se, mais provavelmente, de como as categorias de pessoas eram reconhecidas e tratadas de forma correspondente.

Nesse sentido, a política do reconhecimento na democracia não se refere ao "não-reconhecimento ou ao reconhecimento inadequado" de determinadas categorias de pessoas, como colocou Taylor. Diz respeito à mudança do significado e significância das categorias. Aqueles que ocupavam o poder sentiram-se compelidos a redefinir o status político das mulheres, por exemplo, depois de terem sido persuadidos pelas sufragistas de que recusar o direito de voto às mulheres constituía prática democrática inaceitável. Teriam os homens erroneamente reconhecido as mulheres como suas iguais? Esta pode ser uma maneira de colocar a questão, porém acho que é diferente considerar a forma pela qual os homens constituíram, pelos poderes de que foram investidos pelo Estado, o status legal da categoria mulher. Eles não reconheceram mal a categoria. Veja-se como, no Ocidente, desde Platão, quando se tratava de articular a categoria da mulher, os escritores procuravam reconhecer cada deficiência, plausível e implausível, como constitutiva da categoria. Dizer que eles consideravam as mulheres de forma errada é considerar as divisões como determinadas e fixas, ainda que terrivelmente mal interpretadas. Com isso, perde-se de vista o fato de que a própria categoria é em grande parte construída pelo homem. A categoria é constituída por aqueles que ocupam o poder, segundo sua própria imagem da mulher e que tiveram de ser convencidos a mudar o significado da categoria ${ }^{2}$. O que significa dizer que a extensão dos direitos democráticos equivaleu à redução da eficiência política das categorias como ferramentas de exclusão e instrumentos de poder.

É por isso que eu sinto que, aqui, a questão política, assim como a educacional, refere-se à construção contínua da categoria. Com sua filosofia do reconhecimento, Taylor sugere que existe uma verdade sobre a categoria que só necessita ser reconhecida, à medida que as vendas do preconceito comecem a cair de nossos olhos. Taylor não discorda das categorias, ao menos não diretamente. Ao denunciar

2 Donna Haraway faz uma crítica ao que a ciência fez da mulher. Haraway escreve que, quando se trata de uma análise crítica sobre gênero, "nem mesmo existe um estado como 'ser' mulher, em si própria uma complexa categoria elaborada em um discurso científico sexual contestado e outras práticas sociais" (|99|, p. | 55). 
"o aprisionamento de uma pessoa em um modo de ser falso, distorcido e limitado", direciona nossa energia moral e política no sentido de liberar o modo de ser verdadeiro, preciso e ilimitado de uma pessoa. Meu receio é que isso seja de pouca valia para nos dissuadir da crença de que, se não fosse por essa tradição de reconhecimento inadequado, enxergaríamos a natureza (verdadeira) uns dos outros e compreenderíamos exatamente as qualidades que hoje estão encobertas pelas forças sociais. De forma que, ao mesmo tempo que dou as boas-vindas ao interesse de Taylor por modos de ser ilimitados, não posso deixar de sentir que o trabalho político e educacional que requer nossa atenção imediata é a forma como as categorias pelas quais conhecemos e nomeamos uns aos outros foram formadas, categorias essas que fornecem todas as indicações de continuar a servir, dentro da política da identidade, como forma de diferenciar a distribuição de poder nesta sociedade.

Enquanto eu desejo que os alunos se detenham mais sobre tudo que se relacione a como as categorias são construídas ("discurso científico e outras práticas sociais" de Haraway), Taylor sente que o melhor que se pode esperar na educação é o "estudo cultural comparativo", que nos permitirá identificar o "valor relativo das diferentes culturas" (p.73). Parece-lhe que essa abordagem diminuirá o etnocentrismo ou, como ele coloca, "deslocará nossos horizontes nas fusões resultantes"; destinase também a verificar "julgamentos inautênticos de igual valor" quando se avaliam outras culturas (p.73). Com certeza, eu responderia que não há nada de errado em estudar como as outras pessoas vivem, em nos tornarmos alunos criteriosos e críticos das artes e ofícios sutis do mundo. Ainda assim, questiono a insistência antirelativista de Taylor de que deveríamos refinar nossa capacidade para poder compararo valor relativo das culturas. A que ele se refere, me pergunto, quando fala sobre o "horizonte supremo a partir do qual o valor relativo das diferentes culturas poderia ser visível" (p.73)? Isso traz à mente a excitação que se sente ao subir os degraus do Museu Britânico, quando se está prestes a ficar na presença das maravilhas culturais do mundo, e mesmo assim, em um certo nível, instituições veneráveis como o museu poderiam ser caracterizadas como os repositórios, que dominam o horizonte, da perspectiva suprema do Ocidente na comparação das culturas. Em um nível mais simples, isso faz lembrar os esforços protomulticulturais para ensinar aos jovens sobre como os nativos americanos introduziram o milho, a batata, o tomate e o tabaco no Ocidente, como se o valor de um povo devesse basear-se na sua contribuição para nossa mesa e nosso bem-estar ${ }^{3}$.

3 Não se trata de invalidar aquela contribuição. Para uma análise ampla sobre "como os índios das Américas transformaram o mundo", ver Jack Weatherford (1988). 
O valor relativo dessas diferentes culturas torna-se pequeno diante das conquistas do Ocidente, diante de seu poder de reunir e julgá-las como parte de sua função educativa maior. De minha parte, proponho que nos tornemos estudiosos das distinções que esse arranjo educacional tanto fez para construir, em exposições de museus e livros didáticos sobre estudos sociais, estudiosos de como, à maneira de Edward Said, por exemplo, o Ocidente criou o Oriente como uma categoria, além de constituir a si próprio no processo (1978). A política do reconhecimento que defendo aqui é a de reconhecer e contestar a fabricação histórica de categorias que nos identificam, por exemplo, como mulher e francesa, porém que obscurecem, insistimos com veemência, quem somos em outro nível, como seres humanos completos ${ }^{4}$.

Sem dúvida, Taylor distingue entre as esferas pública e privada do reconhecimento, porém ele também combina as duas ao falar de uma "política da diferença", em que "o que somos solicitados a reconhecer é a identidade única desse indivíduo ou grupo, sua distinção diante de todas as demais pessoas" (1994, p.38). Falar sobre a identidade única de um grupo, como se essa identidade se formasse como flocos de neve, de que não há dois iguais, negligencia o aspecto de como essa identidade é formada dentro das poderosas relações sociais que moldam como uma pessoa cresce mulher e francesa. Taylor reconhece a ação das influências sociais sobre o indivíduo, assim como sobre o grupo, mas não vê essas influências, como eu vejo, como o próprio cerne da política do reconhecimento. $\bigcirc$ que é político com relação ao reconhecimento é a forma como se dá o debate sobre como um grupo é constituído pelas influências sociais e como um grupo é denominado e colocado em uma estrutura social maior. Sendo assim, este processo exige atenção educacional. $\bigcirc$ que equivale apenas a dizer que a política do reconhecimento não nos deve levar a tentar reconhecer, de alguma forma, quem uma determinada pessoa realmente é, principalmente diante das representações pós-modernas de quão parcial, quão fragmentado aquilo que tomamos por self pode ser. Uma educação

4 Maxine Hong Kingston apresenta um exemplo maravilhoso da complexidade do reconhecimento, ao falar a leitores de origens étnicas mistas sobre as suas porções que são chinesas: "Chineses-norte-americanos, quando vocês tentam compreender que partes de vocês são chinesas, como vocês separam o que é peculiar à infância, à pobreza, a insanidades, uma família, sua mãe que marcou o crescimento de vocês com histórias, do que é ser chinês?" ( 1975, p.5-6). A alteridade está manifesta, designada, confusa, orgulhosamente mantida. Uma pessoa só consegue olhar no espelho e imaginar. Ou a pessoa pode esperar um pouco mais das escolas para compreender como essas questões sobre identidade constituem momentos tanto da história pessoal quanto de uma história política mais ampla. 
voltada para a política do reconhecimento faria muito melhor concentrando-se na ciência da raça que surgiu no século passado e que continua no presente século. Deveria examinar as políticas de imigração e o tratamento dado pela mídia às muIheres. Deveria deter-se sobre as leis, em Quebec, referentes a idiomas que restringem o uso do inglês nos avisos públicos. Deveria considerar como a idéia de nação se alinha com raça, e como a cultura passou a servir de mediadora entre os dois termos, ao dividir o mundo entre nós.

Um esforço educacional dessa ordem tende a afetar o modo como eu reconheço a mim mesmo e aos outros, ainda que trabalhe mais diretamente sobre a compreensão do próprio processo de reconhecimento. Porém, uma vez que a política do reconhecimento, como Taylor descreve, está na base do espírito de iniciativas multiculturais nas escolas, devo analisar como a atenção à construção das categorias, no espírito do impulso inicial de Weil de compreender e agir sobre as obrigações que nos ligam, poderia coadunar-se com esse conceito público progressista, assim como com seus críticos mais ácidos.

\section{MULTICULTURALISMO EM AÇÃO}

○ Canadá oferece um excelente ponto de partida para considerar-se o multiculturalismo em ação. Embora haja um ressurgimento da crítica da direita sobre o assunto, o país ainda está compreensivelmente orgulhoso da política oficial, adotada como política nacional em 1971, que veio a se transformar na Lei do Multiculturalismo Canadense (Canadian Multiculturalism Act) em 1987. Atualmente, o governo está ativamente comprometido com o patrocínio de grupos culturais da comunidade, eventos étnicos e programas escolares correspondentes - em 1996 , por exemplo, o governo contribuiu com uma verba de 18,5 milhões de dólares. Esse ato legislativo destina-se a garantir que as pessoas tenham a "liberdade [...] de preservar, promover e compartilhar suas heranças culturais" (Canada, 1987, p. I8). Naquilo que alguns vêem como uma atitude paternalista, a lei reconhece um modo de ser de origens étnicas mistas entre a identidade dos cidadãos da nação, não simplesmente como um acréscimo que enriquece, mas como um elemento definidor: "O Multiculturalismo é uma característica fundamental da herança e identidade canadenses e [...] serve de fonte valiosa para moldar o futuro do Canadá" (p. I8). Depois de um século de políticas de imigração racialmente restritivas, isso poderia de fato tornar-se, como Taylor observaria, um passo político para uma ampliação do reconhecimento. E a lei certamente exerceu um impacto sobre a educação. 
Diversas comunidades canadenses deram início a programas de idiomas herdados, depois de esforços por vezes tempestuosos sobre o apoio público a outros idiomas além do inglês e do francês (Cummins, 1989). Depois de anos de programas experimentais, a Universidade British Columbia agora permite que os alunos estudem punjabi, mandarin ou japonês no ensino médio. Nas aulas de literatura, está sendo usada uma nova geração de antologias literárias que amplia as tradições anglo-norte-americanas da literatura de língua inglesa para um novo espectro de vozes e experiências 5 . Em Ciências e Matemática, que às vezes se declaram isentas de interesses multiculturais, são agora oferecidas aulas sobre inventores, cientistas e matemáticos não europeus (Price, 1992, p.3 I). Com isso, em nome do multiculturalismo, os educadores procuraram ampliar a representação escolar daqueles que constituem a nação.

Mais recentemente, uma segunda abordagem educacional da política de identidade nas escolas canadenses tem sido confrontar o flagelo do racismo por meio de programas anti-racismo. Os secretários da educação das províncias canadenses que tentaram implementar programas anti-racismo seguiram dois caminhos. $O$ primeiro procura ajudar os alunos a lidar com o racismo que encontram na escola e na comunidade. $\bigcirc$ secretário da educação de British Columbia, por exemplo, recomenda aos professores do ensino médio que procurem maneiras de "abordar explicitamente e fornecer estratégias intervencionistas para eliminar estereótipos, preconceitos, discriminação e racismo" (Canada, 1992, p.47). Determina formas de treinamento de assertividade que permitirão aos alunos "intervir em casos de constrangimento racial e cultural" (p.47). Uma vez que o racismo diz respeito a muito mais do que a ação de indivíduos grosseiros e prepotentes, um segundo curso de ação procura identificar como o racismo sistêmico moldou, durante muito tempo, as políticas e práticas de imigração, moradia, emprego e educação.

Adotando essa linha, o secretário da educação e treinamento de Ontário emitiu a declaração "Anti-racismo e eqüidade etnocultural nos conselhos de educação", a qual determina que o currículo escolar não só reconheça a diversidade, mas que lute contra sua própria tradição educacional de etnocentrismo:

5 Ver Borovilos ( 1990), para um exemplo, e Greenlaw ( 1993), para uma crítica. Diana Brydon adverte que "corremos o risco de que a nova moda de 'terceiro mundo', 'minoria' ou 'literaturas marginalizadas', como têm sido chamados, meramente introduzam versões mais sutis de 'disparidade incorporada' em lugar de desafiar uma organização de discurso que justifica o status quo"(| 989, p.91). 
O currículo anti-racista permite um equilíbrio de perspectivas. Torna todos os alunos capazes de ver a si próprios refletidos no currículo escolar e fornece a cada estudante o conhecimento, habilidades, atitudes e comportamentos necessários para viver em um mundo complexo e diversificado. Conscientemente examina e desafia a natureza eurocêntrica do currículo e da sociedade em que os jovens estão se desenvolvendo. (Canada, 1993, p. 12)6

Observe como o reconhecimento aqui opera nas duas direções. $\bigcirc$ currículo se abre para uma maior diversidade de experiências, ao mesmo tempo que olha com olhos críticos para sua própria tradição hermética.

A passagem da educação multicultural para anti-racista parece ser uma medida promissora na investigação de como as coletividades são construídas. Para mim, no entanto, isso não basta. Ver como um mapa oferece uma projeção eurocêntrica de uma fantasia imperialista, que enxergava a civilização irradiando-se a partir de um centro europeu, é uma coisa; porém, o mapa precisa também se transformar em uma lição de como o Ocidente não só olhava para o mundo como se fosse sua propriedade, como também designava o outro e em seguida a si próprio, como se as diferenças fossem reflexos da natureza, não buscando seu significado na história. Assim, nessa educação multicultural, anti-racista, ainda está por vir a história do investimento aprendido sobre a significância das diferenças e divisões no seio da humanidade.

Estou pedindo que os alunos adquiram alguma compreensão de como o mundo veio a ser dividido dessa forma. Isto parece crucial para a apreciação, crítica e explicação do jogo político da identidade no mundo atual. É muito improvável que eu seja o único a pedir que isso seja acrescentado à agenda educacional multicultural e anti-racista. James Banks que, por exemplo, liderou por longo tempo a educação multicultural norte-americana, compartilha essa determinação de focalizar a formação das categorias pelas quais somos identificados ${ }^{7}$. "Os alunos

6 George Sefa Dei, do Instituto de Estudos da Educação Ontário, fala sobre a necessidade de "problematizar os privilégios e supremacia do homem branco eurocêntrico, e as conseqüentes desigualdades sociais em nossa sociedade pluralista" (1993, p.37). Em sua abordagem anti-racista, ele coloca ênfase na história: "A eficácia do trabalho anti-racista nas escolas dependerá da compreensão histórica clara das estruturas, fatores e questões institucionais que contribuíram para a educação discriminatória e etnocêntrica dentro do sistema educacional" (p.39). Para uma análise e aplicação dos programas curriculares multiculturais, anti-racistas e póscoloniais nas salas de inglês em Ontário, consultar Greenlaw ( 1993).

7 Ver Banks e Banks ( 1995) sobre um surveyacerca da educação multicultural na América. 
deveriam ter oportunidades", recomenda, "de investigar e determinar como as hipóteses culturais, estruturas conceituais, perspectivas e tendências dentro de uma disciplina afetam as formas pelas quais o conhecimento é construído" (1993, p. I I). Em um artigo posterior, Banks propõe que os alunos aprendam como a mudança do significado de raça reflete a luta pela construção da diferença. $\bigcirc$ autor não está buscando uma celebração multicultural da diversidade, mas, sim, uma transformação do modo pelo qual os alunos entendem as categorias que impõem divisões. Situa de que forma os "reconstrucionistas da raça" afro-norte-americanos, como ele denomina Kelly Miller, W. E. B. Dubois e outros, deslocaram o significado do conceito para fora da influência exclusiva de uma sociedade bem-educada e instruída, porém profundamente racista (p. 17- 18). Procura inspirar os alunos, por meio desse comprometimento com o passado, com a reconstrução contínua da raça como um processo de que eles são capazes de participar:

Os alunos devem examinar as formas pelas quais a construção da raça reflete o contexto social, os tempos históricos e a estrutura econômica da sociedade. Os alunos devem compreender também que o conceito de raça ainda está em processo de mudança e reconstrução. (1995, p.23)

A questão educacional para Banks, e sem dúvida para mim também, é tornar a história política da diversidade parte do programa escolar. Os alunos precisam ter alguma compreensão sobre o longo processo aprendido pelo qual a cultura, raça ou nação (até mesmo quando se sobrepõem e se projetam um sobre o outro) continuam a ser investidas de diferenças significativas. Esses interesses conceituais não precisam diminuir a importância do aprendizado sobre a diversidade cultural que continua a moldar o continente norte-americano. Estou só pedindo que entremos cuidadosamente na política de reconhecimento e diferença, indagando pela formação das categorias segundo as quais nos identificamos. Só temos de pedir aos alunos que deixem de lado a idéia de que existe uma verdade, essência, ou cerne, em qualquer categoria; por meio da pesquisa de campo ou multimídia interativa, não estamos prestes a desvendar a verdade que jaz sob os rótulos.

Porém, a essa altura, muitos alunos já estão envolvidos na tarefa de reescrever as categorias. Estão buscando, comecei a suspeitar durante uma noite de variedades em uma escola de ensino médio de Vancouver, um outro tipo de política da identidade e reconhecimento, ou algo do gênero. Os mais hilariantes momentos da noite para esse público de alunos e suas famílias aconteceram quando um grupo de dançarinos Bhangara, formado e dirigido por alunos, entrou correndo no palco em trajes feitos à mão e apresentou uma forma de música pop do leste indiano. 
Não se tratava de dança folclórica multicultural, tampouco o objeto era a preservação de uma cultura distante. Tratava-se, ao menos da forma como eu senti entre os gritos e aplausos da platéia, da afirmação e invenção que fazia parte da vida desses alunos. A dança forma uma declaração muito real e sincera sobre onde é aqui, no sentido de quem é homenageado, e do que pode ser reconhecido em um auditório escolar. Se, naquela noite, na platéia houvesse especialistas crítico-teóricos, a dança Bhangara, seguida por música rap e peças soul, em um sincretismo cultural, poderia ser entendidas como definidora do "chicpós-modernista transgressor [...] a sobreposição de códigos", que, para Peter McLaren, distingue as identidades limítrofes da época ${ }^{8}$. Aquele auditório, repleto de alunos entusiasmados, pode ser tomado por alguns como uma força incipiente na política da identidade, porém ele sintetizava e servia de amostra de seu caminho rumo a um novo conjunto de raízes culturais. Os alunos representavam as possibilidades de redefinir e retrabalhar as categorias. Desejo somente complementar esse trabalho engenhoso com lições de apoio de Geografia, História, Literatura e aulas de Ciências sobre a formação das diferenças com que eles brincam e às quais se opõem. Mas a política da identidade foi fomentada com uma reação conservadora contra o multiculturalismo que, na parte final, desejo considerar como fator que também acrescenta peso à necessidade do tipo de aulas sobre a construção das categorias que tenho defendido.

\section{A REAÇÃO CONTRA O MULTICULTURALISMO: BISSOONDATH E SCHLESINGER}

Se os defensores do multiculturalismo procuram uma política do reconhecimento com base no respeito às diferenças, não estão tão distantes de seus melhores críticos. Aqueles que não querem nem saber do muticulturalismo defendem o respeito às diferenças por meio da preservação e proteção da diversidade que, segundo crêem, define a nação. Os críticos conservadores do multiculturalismo tornaram-se cada vez mais determinados a resgatar e redimir a nação em perigo. Nessa linha de pensamento, o romancista Neil Bissoondath e o historiador Arthur Schlesinger publicaram livros que advertem sobre a fragmentação que sobrevirá ao

8 McLaren argumenta que "os estudantes devem ter a oportunidade de construir identidades limítrofes... espaços intersubjetivos de tradução cultural - espaços multivalentes do ponto de vista lingüístico, onde haja diálogo intercultural" (1994, p.65). Diversos alunos já fizeram o trabalho de construção, de forma que o que podemos oferecer são oportunidades para uma compreensão maior no trabalho escolar e outros aspectos da formação da identidade. 
estado multicultural. Em Vendendo ilusões: o culto do multiculturalismo no Canadá, Bissoondath deixa claro que está cansado da banalidade que cerca o tema. $\bigcirc$ festival caribenho realizado anualmente em Toronto deixa-o indiferente. Ele critica os subsídios aos guetos culturais e zomba dos "excessos de sensibilidade" que conseguiram infiltrar-se no governo e nas universidades (1994). Queixa-se de que, sob esse patrocínio, "a cultura torna-se um objeto a ser exibido em lugar de ser o coração e alma dos indivíduos que a compõem” (p.88). Com habilidade, demonstra, da mesma forma que eu tentei fazer com o trabalho de Charles Taylor, que o multiculturalismo não pode possivelmente "acomodar a realidade complexa" da vida das pessoas, ao que ele acrescenta que "a herança cultural nem sempre é uma coisa agradável” (p.87-88). É fácil ver também que a intervenção governamental na cultura com certeza rouba ao menos um pouco de sua expressão espontânea e autêntica.

Não obstante, ao lançar essa crítica, Bissoondath põe em prática sua própria política de identidade. Ele "recusou o rótulo de étnico e", segundo as palavras do resumo da contracapa, "procurou evitar o peso da origem étnica mista - um peso que o identificaria como um canadense-trinitário-da-Índia-ocidental residente no Quebec". O autor parece determinado a tornar aparentes as categorias somente para rejeitá-las. Tem aquele elemento voluntário e individualista que Taylor manteve no sentido de um diálogo. Você pode propalar seus vínculos étnicos quando você e seu editor reconhecem o quanto a identidade ligada à sua raça acrescenta ao interesse em sua crítica daquilo que se destina a proteger seus interesses? Por meio de uma comparação provocativa, ele determinaria que se trata de uma identidade fora dos limites do governo e da política do reconhecimento: "Minha vida sexual só diz respeito a mim, dizemos, por exemplo. No entanto, muitos de nós parecemos depender do Estado para o significado de selfque advém do reconhecimento oficial de nossos antecedentes culturais" (1994, p.2 13). Trata-se de algo correto para heterossexuais dizerem, alguns poderiam argumentar. Porém, no Canadá, dentre as diversas formas de intervenção pública, inclui-se o confisco de literatura gay por funcionários da alfândega na fronteira do país. O Estado está profundamente envolvido no sentido de disciplinar, para não dizer policiar, a política de identidade segundo a qual vivemos. Podemos recusar essa política ao declarar unilateralmente a independência do self.

Bissoondath dirige seus apelos à nação imaginária e unificada do passado, atualmente ameaçada pelo multiculturalismo: "Ao erradicar o centro, ao evocar incerteza sobre o que e quem é canadense, o multiculturalismo diminuiu todo o significado dos valores canadenses, do que é ser um canadense" (I 994, p.7I). Ele 
não demora em reconhecer que ser um canadense sempre foi uma miscelânea de conjecturas, normalmente vinculada com ordem, bom governo e respeito pelos Mounties. No entanto, contrapõe que o multiculturalismo só consegue piorar o tema da autodefinição nacional.

Se o multiculturalismo dificultou a questão da identidade, isso, a meu ver, só tende a torná-la melhor, pois a incerteza sobre quem é canadense significa adotar uma postura muito menos assertiva em relação a quem é de fato canadense. Este é o momento de se reconhecer que a nação é constituída por tudo que contém, e não somente por aqueles situados em um centro ou origem imaginários; a nação é uma organização política do espaço, e não uma qualidade de caráter que só precisa ser adequadamente reconhecida9. Já deveríamos ter deixado para trás a era em que os especialistas e eruditos costumavam orgulhar-se da habilidade com que conseguiam nomear o caráter de uma nação, na forma de raça e cultura. E quanto ao receio expressado por Bissoondath de que haveria uma "diminuição [...] do significado dos valores canadenses", poderiam esses valores ser os mesmos que impediam mulheres, chineses-canadenses e os primeiros habitantes das nações de votar, que se recusavam a reconhecer mulheres como pessoas aos olhos da lei, e que continuam a contestar as reivindicações sobre a terra dos primeiros habitantes das nações? ${ }^{10}$ Ao longo dos anos, as alterações desses valores resistiram consistentemente em nome de preservar aquilo que era ser canadense. Precisamos honrar aqueles que vivenciaram essa história invocando a formação da nação, em lugar de procurar ver de que forma cada um de nós se mantém fiel a algum tipo de centro nacional da nação.

Esse receio de que o centro não consiga ser preservado tem sua contraparte norte-americana na bem recebida crítica do multiculturalismo, A Desunião da América, de autoria do decano dos historiadores norte-americanos, Arthur Schlesinger ( 1992). Extremamente alarmado com essa ameaça à estrutura norte-americana, Schlesinger vê o restabelecimento da poderosa associação de raça e nação como a única esperança. Tomou a iniciativa inspirado em Hector St. John de Crèvecoeur (1963) em Cartas de um fazendeiro americano, publicadas à época da Revolução

9 A observação final de Bissoondath, exigindo "uma mistura [das diferenças] em uma nova visão do que é ser canadense... em que diferenças inerentes fundem-se facilmente... e cada indivíduo é um canadense, não diluído e não dividido" parece almejar por um significado metafísico e apolítico de nacionalidade ( p.224).

10 Ver Alison Prentice et al. (1982). 
Americana. "Aqui, indivíduos de todas as nações", escrevia Crèvecoeur, "amalgamam-se em uma nova raça de homens" "I. Schlesinger adota esse tema de uma nova "raça" encorajado por "Smelting pot" (Cadinho de raças), de Emerson, e "Credo americano", de Mydral. Prepara um ataque implacável àquilo que denomina de "culto da etnicidade", que "rejeita a visão unificadora de indivíduos de todas as nações fundidos em uma nova raça" (p. 15$)^{12}$. O mito raça-e-nação assume uma importância redobrada no livro de Schlesinger. Assume que, no primeiro exemplo, a identidade é uma questão de escolha, pelo fato de estar na América do Norte:

A maior parte dos membros de grupos minoritários nascidos na América do Norte, brancos e não brancos, embora possam nutrir sentimentos por heranças particulares, ainda assim vêem-se basicamente como norte-americanos e não originalmente como irlandeses, húngaros, judeus, africanos ou asiáticos. (p. 19)

Esse mito de uma nova identidade no novo mundo revelou-se um tema literário poderoso, de Filho nativo a Clube alegre e de sorte. Aqueles que escolheram, ou foram escolhidos pela América do Norte, tiveram de aprender os termos segundo os quais seriam admitidos ao abrigo. Schlesinger reforça essa idéia ao nomear a terra comum, sem levar em conta a contribuição de outras culturas: "A tradição anglo-saxônica protestante foi, durante dois séculos - e em aspectos cruciais ainda é - a influência dominante sobre a cultura e sociedade norte-americanas" (p.28). E os portadores dessa influência? "Nossas escolas públicas em particular", ele aponta, "têm sido ótimos instrumentos de assimilação e ótimos meios de formação da identidade norte-americana" (p. 17). Como Schlesinger consegue imaginar que a identidade norte-americana possa ser qualquer coisa exceto dividida? As escolas sempre ensinaram os jovens a traçar as linhas que os identificam como norte-americanos, no mínimo, em gênero, raça, cultura e classe ${ }^{13}$.

Contudo, as escolas de hoje estão realmente negligenciando a América do Norte, aponta Schlesinger num ataque que às vezes soa mal-humorado e exaspe-

II Schlesinger (1992, p. 12). Vale a pena mencionar que, logo depois, Crèvecoeur teve de deixar sua nova pátria e os colegas norte-americanos, por recusar-se a depor durante a Revolução Americana, uma decisão que lhe custou a esposa e filhos.

12 Esse significado, de forjar uma nova raça, pode ser encontrado na peça de Israel Zangwill, The Melting pot, da virada do século, que revela sua leitura ultrapassada e ingênua de raça: "A América do Norte é o cadinho, o grande caldeirão racial de Deus, em que todas as raças da Europa estão se fundindo e se convertendo" (citado por Shipman, 1994, p. I23).

13 Ver, por exemplo, a coleção McCarthy e Crichlow (1993). 
rado, ao introduzir programas afrocêntricos que focalizam as civilizações e realizações do continente africano ${ }^{14}$. Schlesinger demonstra pouca paciência com programas que "rejeitam as origens essencialmente européias da cultura norte-americana" e que, a seu ver, "falsificam a história" (p. 1 36). Com relação a esses programas multiculturais afrocêntricos, o autor adota uma postura do tipo vamos esclarecer uma coisa:

Sejam quais forem os crimes cometidos pela Europa, esse continente é também a fonte - a única fonte - dessas idéias independentes de liberdade individual, democracia política, o império da lei, direitos humanos e liberdade cultural que constituem nosso mais precioso legado e a que a maior parte do mundo aspira. São idéias européias, e não idéias asiáticas, africanas, ou do Oriente Médio, exceto por adoção. (p. I27, grifo do original)

Sua certeza sobre a exclusividade das idéias - "idéias européias, não asiáticas" - é inquietante, considerando-se o movimento de idéias durante os séculos. Mas, então, também o é seu aparente esquecimento histórico, não dos "crimes particulares da Europa", mas de como "essas idéias libertadoras" foram muitas vezes usadas para perpetuar injustiças. As realizações desse continente foram subscritas pela negação habilmente sustentada de "liberdade individual, democracia política, o império da lei, direitos humanos e liberdade cultural" para um número considerável de pessoas.

Schlesinger está celebrando os ideais dos vencedores, ao mesmo tempo que deixa de reconhecer que a luta para estender essas idéias à nação como um todo foi uma batalha intelectual contra a qual muitas pessoas, que fazem parte da "única fonte", lutaram por longo tempo. Isto não significa que devamos rejeitar as

I4 Molefi Kete Asante caracteriza a abordagem afrocentrista, ao declarar que "todo conhecimento resulta de uma ocasião de encontrar um lugar... $\mathrm{O}$ afrocentrista procura descobrir e usar esses paradigmas de códigos, símbolos, temas e círculos de discussão que reforçam a centralidade dos ideais e valores africanos, como uma referência válida para obter e analisar dados" (1990, p.5-6). George Dei fala sobre o desafio de ensinar sobre o lugar da África no mundo depois de tantos anos de representação inadequada (1993, p.43-46). Em Martin Bernal (1987), é possível encontrar que as influências africanas e semíticas no Ocidente, por meio da cultura grega da Antigüidade, foram deliberadamente obscurecidas no século passado por intelectuais. Por outro lado, Henry Louis Gates denuncia "demagogos e pseudointelectuais entre" os defensores afrocentristas (1993). A mais notória das propostas que Gates ataca é a African-American Baseline Essays, publicação que pode ser obtida nas escolas públicas de Portland; ver Hughes (1993, p. I30-15I). Ver Murrell (1993) e Perry (1993), para obter análises mais favoráveis sobre as aventuras dos currículos afrocêntricos. 
realizações da cultura européia. Mas poderíamos resistir a elas para beneficiarmonos um pouco mais daquela inquietadora perspectiva histórica no curso daquelas idéias libertadoras. Tudo dito e feito, o argumento de Schlesinger desce à mais básica das submissões: "Decorridos dois séculos, o nacionalismo continua a ser a mais importante emoção política do mundo (p.47) $)^{15}$. Que a nação não pareça amar todos os cidadãos e tenha forçado a adoção de um self vinculado à etnia para muitos deles, salta imediatamente aos olhos de um historiador. Porém, da mesma forma, uma pessoa poderia decepcionar-se ao ver aqueles que não amam as influências dominantes da cultura norte-americana acusados como se constituíssem uma ameaça à democracia. Embora o nacionalismo certamente tenha tido seus momentos de liberação, anticoloniais, os perigos de suas versões étnicas nunca estiveram tão visíveis. E estabelecer o nacionalismo como fundamento de uma nova raça - "ainda o que se pode esperar de melhor" - no dizer de Schlesinger - só faria colocar a América do Norte sob a maldição daquela gasta parada de nacionalismo, liderada pelas raças inglesas e francesas durante todo o século passado (p. |38) ${ }^{16}$.

Usar a metáfora da raça para evocar a unificação da nação sob um só Deus contribui pouco para honrar a história de uma nação formada tragicamente a partir das divisões raciais. Nas mãos de Schlesinger, a política da identidade torna-se uma exigência de que o povo se identifique com a cultura dominante, honre sua história e historiadores, submergindo naquilo que é considerado como a identidade autêntica e essencial da nação. Pode parecer também que Schlesinger receie tanto pela nação quanto pela dominação. No entanto, seus argumentos baseiam-se na confusão que Taylor pouco fez para esclarecer, uma confusão que permite que a identidade autêntica e duramente conquistada pelo indivíduo torne-se a alma do coletivo. Ao mesmo tempo que critico Bissoondath e Schlesinger por rejeitarem as iniciativas multiculturais, considerando-as nocivas para a saúde da nação, meu intento aqui não foi o de defender o reconhecimento necessário e ético da pluralidade de nossas comunidades. $\bigcirc$ corretivo educacional, a meu ver, ainda repousa na busca daquilo que entendo ser a investigação de Simone Weil sobre os interesses humanos servidos pelos interesses coletivos.

I5 Para consultar um estudo sucinto do trabalho que conecta Schlesinger e Hirsch por meio da historiadora educacional Dianne Ravitch, ver Seixas (1993, p.236-237).

I6 É interessante observar que o geneticista Dobzhansky fala a respeito de novas raças que estão em processo de formação, com a Europa "bem avançada no sentido de fundir-se em uma única raça" (1962, p.279), o que parece ser um obscurecimento comum da linguagem (científica) figurativa e literal de raça e cultura. 
Para Weil, a necessidade de raízes nos leva a julgar nossas identificações, testar sua afirmação de vida e liberdade, seus poderes de exclusão e inclusão. Esse engajamento crítico com nossa identidade equivale à sua própria maneira de ser enraizado neste mundo. Atualmente, na França, uma outra líder intelectual do país, Julia Kristeva, foi levada, ao reconsiderar a questão da nacionalidade, a se dar conta de como todos somos, em algum nível, "estranhos para nós mesmos" ( $199 \mid$ ). Ela descreve uma dinâmica interna que produz essa experiência de auto-estranhamento: "O estrangeiro chega quando a consciência de minha diferença surge e desaparece quando todos nós nos reconhecemos como estrangeiros, insubmissos a laços e comunidades" (p. I). Em vez da segurança de um local, Kristeva é conduzida por uma sensibilidade pós-nacional que descobre, declarada de maneira sucinta nas palavras de Meleagro de Gadara, do primeiro século a.C: "A única pátria, estrangeiro, é o mundo em que vivemos; um único Caos deu origem a todos os mortais" (p.56). Kristeva não está pronta, como se percebe, a abrir mão das distinções de nacionalidade e da França adotada por ela, mas, ao menos, ela chegou a questionar como o estrangeiro e a comunidade são constituídos ${ }^{17}$.

Fazer um estudo das divisões segundo as quais vivemos é uma educação arriscada. Pode fazer com que uma pessoa não consiga mais ficar à vontade, despreocupada, com seu próprio eu ou lugar. Esse foi o exemplo da própria vida de Weil, uma vez que ela estava tanto de acordo com seu país ao escrever sobre a necessidade de patriotismo, quanto forçada a se exilar como judia, na época em que o governo Vichy, da França, colaborava com os nazistas. Eu diria que a educação não tem o menor interesse em distanciar-se da vida própria de uma pessoa e daquilo que chamamos pátria. Nós estamos, a um só tempo, sujeitos às coletividades designadas de nossa existência e com a possibilidade de torná-las objetos de estudo que são sempre formas de auto-investigação, que podem originar expressão refletida e criativa. Vivemos sempre dentro de uma política de reconhecimento e identidade. Temos agora que nos tornar alunos mais sábios sobre como essa política opera, mesmo se isso exigir que nos afastemos de nós mesmos em um

17 Salman Rushdie também adota esse tema de estar à vontade com esse senso de distância, lembrando-nos de que os poderes do escritor deslocado não são somente uma questão de ficção que está escrita. Em seu estudo sobre "pátrias imaginárias", Rushdie evoca as memórias desses estrangeiros produtivos e provocativos como Swift, Conrad e Marx, ao mesmo tempo que exalta sua própria identidade "plural e parcial", nascido em Bombai e com laços na Inglaterra ( $199 \mid$, p. | 5). Ele vê a vantagem do distanciamento que ajuda no aspecto literário de "encontrar novos ângulos pelos quais penetrar na realidade" (p. I5). 
mundo maior, sem amarras, durante somente um minuto ou dois, para poder olhar para trás, sobre como fomos moldados e como moldamos outros. $\bigcirc$ fato de sermos estranhos a nós mesmos, tendo o mundo como nossa única pátria, parece uma tônica própria para repensar as divisões que, por tanto tempo, têm-nos afastado dos outros.

\section{REFERÊNCIAS BIBLIOGRÁFICAS}

ASANTE, M.K. Kemet, afrocentricity and knowledge. Trenton, NJ: New Jersey, 1990.

BANKS, J. A. The Canon debate, knowledge construction, and multicultural education. Educational Researcher, v. 22, n. 5, p.4-14, 1993.

The Historical reconstruction of knowledge about race: implications for transformative teaching. Educational Researcher, v. 24, n. 2, p. I 5-25, 1995.

BANKS, J. A. ; BANKS, C. A. M. (eds.). Handbook of research on multicultural education. New York: Macmillan, 1995.

BERNAL, M. Black athena: the afroasiatic roots of classical civilization. Baltimore, MD: Johns Hopkins Univsersity Press, 1987. V. I : the Fabrication of ancient Greece.

BISSOONDATH, N. Selling ilusions. the cult of multiculturalism. Harmondsworth, UK: Penguin, 1994.

BOROVILOS, J. Breaking throught. a canadian literary mosaic. Scarbotough, ON: Prentice Hall, 1990.

BRYDON, D. New approaches to the new literatures in english: are we in danger of incorporating disparity? In: MAES-JELINEK, H.; PETERSEN, K. H.; RUTHERFORd, A. (eds.). A Shaping of connections. commonwealth literature studies; then and now. Sydney, AU: Dangaroo, p.88-99, 1989.

CANADA. Ministry of Education. The Graduation program working paper: partnerships for learners. Victoria, BC: Bristish Columbia Ministry of Education, 1992.

CANADA. Ministry of Education and Trainning. Antiraqcism and ethnocultural equity in school boards. guidelines for policy development and implementation. Toronto, ON: Queens Printer, 1993.

CANADA. Ministry of Supplies and Services. Multiculturalism, being canadian. Ottawa, ON, 1987.

CRÈVECOEUR, H. St. J. de. Letters from an american farmer and sketches of na eighteenthcentury America: more letters from an american farmer. Toronto, ON: New America Library, 1963. 
CUMMINS, J. Heritage language teaching and the student: fact and friction. In: ESLING, J. H. Multicultural education and policy. ESL in the 1990s: a tribute to Mary Ashworth. Toronto, ON: Oise Press, 1989, p.3-17.

DEI, G. J. S. The Challenge of anti-racist education in Canadá. Canadian Ethnic Studies, v. 25, n. 2, p.36-5। , 1993.

DOBZHANSKY, T. Mankind evolving: the evolution of the human species. New York: Bantam, 1962.

GATES. JR, H. L. Beyond the culture wars: identities in dialogue. Profession. Modern Language Association. n. 93, p.6-11, 1993.

GREENLAW, J. The Postcolonial conception of the high school multicultural literature curriculum. (Doct., dissert.) University of British Columbia.

HARAWAY, D. Simians, cyborgs, and women: the reinvention of nature. New York: Routledge, 1991.

HUGHES, R. Culture complaint. the fraying of America. New York: Oxford University Press, 1993.

KINGSTON, M. H. The Woman warrior. memoirs of a childhood among ghosts. New York: Vintage, 1975.

KRISTEVA, J. Strangers to ourse/ves. New York: Columbia Univesity Press, I991.

MCCARTHY, C.; CRICHLOW, W. (eds.). Race, identity and representation in education. New York: Routledge, 1993.

MCLAREN, P. White terror and oppositional agency: towards a critical multiculturalism. In: GOLDERG, D.T. (ed.). Multiculturalism: a critical reader. Oxford, UK: Blackwell, 1994, p.4574.

MURRELL, P. Afrocentric immersion: academic and personal development of African American males in public schools. In: PERRY T.; FRASER, J.W. (eds.). Freedom's plow. teaching in the multicultural classroom. New York: Routledge, 1993. p.23I-260.

NARSULLA, A. Educators outside Quebec my mystified by hijab ban. Globe \& Mail, p. AI -A4, 1994, Dec. 13.

PERRY, T. I am still thirsty: a theorization and authority and cultural location of Afrocentrism. In: PERRY T.; FRASER, J. W. (eds.). Freedm's plow. teaching in the multicultural classroom. New York : Routledge, 1993. p.26I-270.

PRENTICE, A. et al. Canadian women : a history. Toronto, ON: Harcourt Brace Jovanovich, 1982. 
PRICE, M. Am anti-racist generation: a challenge for education. Education today, v. 4, n. 30/ 3।, p.8-। I, 1992.

RUSHDIE, S. Imaginary homelands. essay and criticism, I981 - 1991. London: Granta Books, 1991.

SAID, E. W. Orientlism. New York: Randon House, 1978.

SCHLESINGER, A. The Disuniting of America: reflections on a multicultural society. New York: Norton, 1992.

SEIXAS, P. Parallel crises: history and the social studies curriculum in the USA. Journal of Curriculum Studies, v.25, n. 3, p.235-250, 1993.

SHIPMAN, P. The Evolution of racism: human differences and the use and abuse of science. New York: Simon \& Schuster, 1994.

TAYLOR, C. Multiculturalism: examining the politics of recognition. Princeton, NJ: Princeton University Press, 1994.

WEATHERFORD, J. Indian givers. how the indians of the Americas transformed the world. New York: Fawcett Columbine, 1988.

WEIL, S. The Need for roots. Boston: Beacon Press, 1952.

WRIGHT, L. Annals of politics: one drop of blood. New Yorker, p.46-55, 1994 July 25.

Recebido em: julho 2002

Aprovado para publicação em: julho 2002 